\title{
Acute appendicitis and dietary fibre: an alternative hypothesis
}

\author{
D J P BARKER
}

\begin{abstract}
This paper examines the time trends in acute appendicitis in Britain in relation to changes in consumption of fibre, meat, and sugar. Knowledge of previous case fatality rates, diagnostic criteria, and management are sufficient to infer general trends in incidence from mortality data. The incidence rose steeply from around 1895 and fell from the 1930s onwards. Contrary to previous statements there is no evidence that disease rates were greatly influenced by the dietary changes in the second world war. It is concluded that dietary changes do not explain the time trends in appendicitis and that the epidemiology of the disease is more readily explained by a primarily infectious aetiology.
\end{abstract}

\section{Introduction}

In 1920 Rendle Short reviewed the rise of appendicitis in Britain during the previous 20 years and the international differences in its frequency. ${ }^{1.3} \mathrm{He}$ concluded that the disease had arisen because of "the relatively less quantity of cellulose eaten on account of the wider use of imported foods." From this conclusion arose the "dietary fibre hypothesis," which was later extended to include a range of diseases commonly seen in Western societies. ${ }^{56}$

This paper compares the time trends in appendicitis in Britain during the past hundred years with the changes in diet. Trends in meat and sugar consumption are discussed together with those in the two main sources of fibre-cereals and vegetables. High intakes of meat and sugar are internationally and historically the principal correlates of a low fibre diet.

\section{Trends in appendicitis}

\section{DEATH RATES}

The Registrar General for England and Wales first abstracted appendicitis as a separate cause of death in 1901 and annual mortality rates are available thereafter.' Figure 1 shows crude average annual mortality rates for appendicitis in England and Wales during 1901-80. Since the trends for males and females are similar, and there is no appreciable sex difference in incidence, data for the two sexes are combined. Death rates rose from 1901 until around 1911, remained steady until the late 1930s, and thereafter progressively declined.

In medical journals at the beginning of the century there was general agreement that the increase in appendicitis in Britain began around 1890-95. The disease was recognised and described long before that but seemingly was rare ${ }^{8}$ Anecdotal evidence and analysis of hospital records suggest that the rise began abruptly. ${ }^{139}$

MRC Environmental Epidemiology Unit, University of Southampton,

Southampton General Hospital, Southampton SO9 4XY

D J P BARKER, PHD, FRCP, director
There is evidence of a similarly abrupt rise in Germany,,$^{10}$ in the French army, ${ }^{11}$ and in Russia. ${ }^{12}$

During the first decade of the century annual death rates in England and Wales rose from around 40 to 70 per million. It is likely that incidence rates rose more steeply than death rates since case fatality fell sharply..$^{13}$ On the other hand, the rise may have been exaggerated by wider recognition of the disease after Fitz's classic account in $1886 .{ }^{14}$ All reports agreed that appendicitis was commonest in children and young adults, some $60 \%$ of cases occurring between the ages of 10 and $30 . .^{15}$

During the first world war death rates from appendicitis were unchanged among children and young adults. Among older women, aged 55 and over, they transiently declined to around $80 \%$ of the prewar values. Data on men are difficult to interpret because of uncertainty about the denominator.

After the first war mortality remained steady. Large studies of hospital records in Britain and America have shown that from around 1920 to 1935 case fatality declined, owing to earlier hospital admission and surgery and the less frequent use of purgatives as initial treatment. ${ }^{15}{ }^{16}$ Although the constant mortality and falling hospital case fatality could have reflected a constant incidence with increased admission of milder cases, it seems likely that incidence rose. There are no incidence data for the general population. Nevertheless, National Health Insurance statistics for Scotland, which relate to adults only, indicate an annual incidence of around 45 per 10000 in 1931-35..$^{\text {is }}$ Adjustment to a total population rate, taking account of the known percentage distribution of cases in children, gives an estimated annual rate of 55 per 10000 .

Death rates began to fall during the 1930s. Figure 2 gives age specific trends by single year from 1931 onwards, rather than the five year averages shown in fig 1 . In all age groups except the very

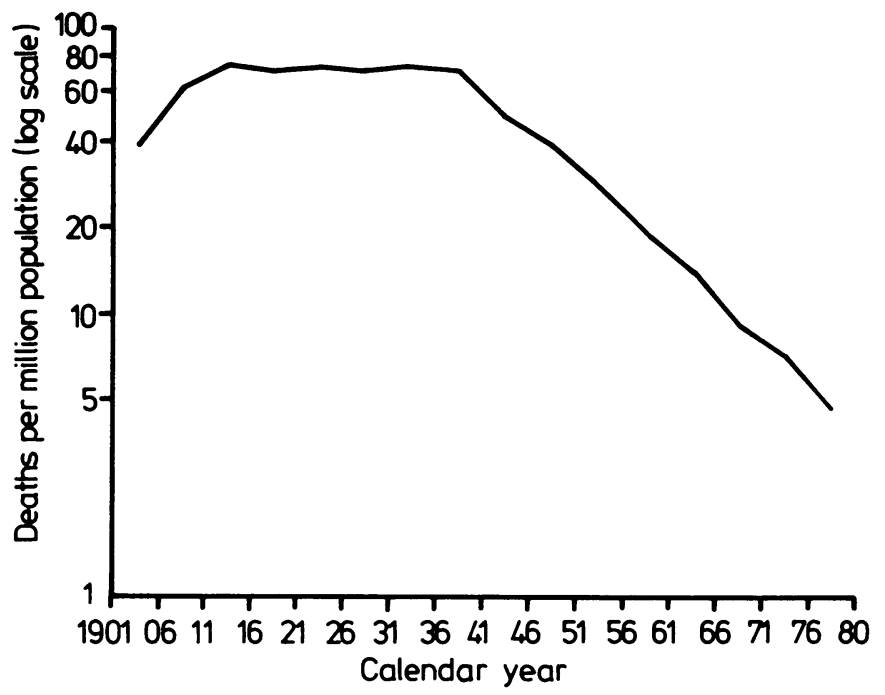

FIG 1-Average annual mortality rates for appendicitis in both sexes combined 1901 80, England and Wales. (Based on Donnan and Lambert. ${ }^{18}$ ) 
elderly, aged 75 and over, death rates were already declining when the second world war began. From 1940 onwards their rate of fall did not greatly change, and the decline continued almost without interruption through the postwar years. Figure 2 shows the low levels reached by 1980 . In the USA there was also a decline in mortality during the 1930 s, shown by the carefully kept records of the Metropolitan Life Assurance Company of New York. ${ }^{15}$

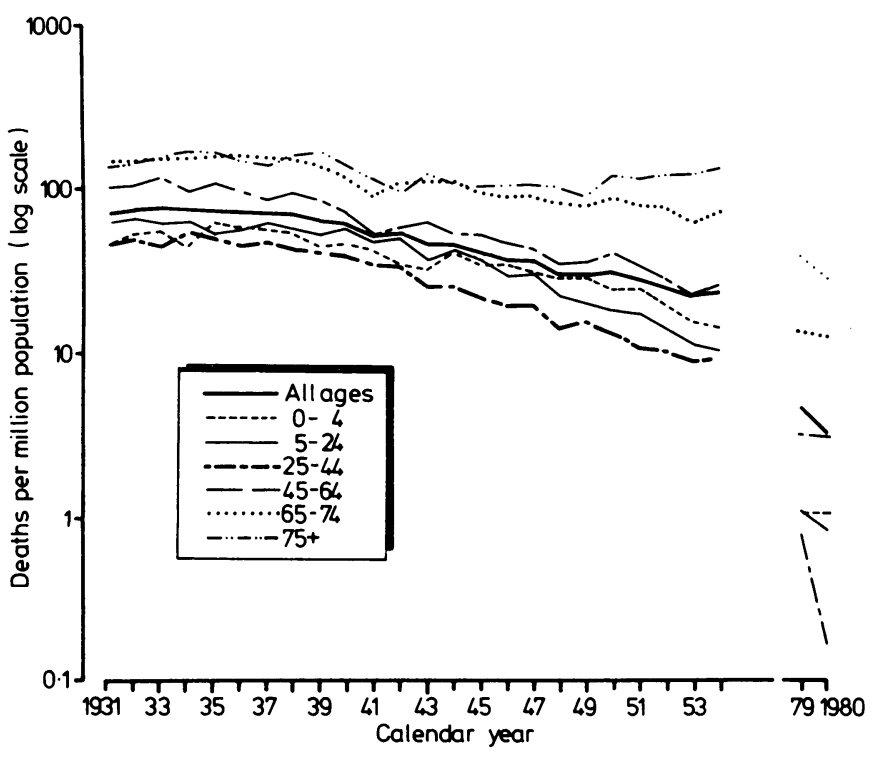

FIG 2-Age-specific annual mortality rates for appendicitis in both sexes combined, 1931-54 and 1979-80, England and Wales. (Rates for 1939-42 based on civilian population, for $1943-9$ on the total population.)

\section{DISCHARGE RATES}

Hospital discharge rates for England and Wales confirm that the postwar decline in mortality reflected a decline in incidence. ${ }^{17}$ Annual discharge rates for acute appendicitis fell progressively from 27 per 10000 in 1959 to 13 in 1980 . Upwards of $96 \%$ of patients discharged with this diagnosis had undergone appendicectomy. Although there was some diagnostic transfer from "appendicitis" to "abdominal pain" during this period, the fall in "appendicitis" was paralleled by a decline in appendicectomy, and it is difficult to argue that it was solely determined by changes in surgical policies. ${ }^{18} \mathrm{~A}$ detailed review of appendicectomies in west Cumberland from 1965 to 1978 showed a steady decline, which was not explicable by a change in the rates of removal of histologically normal appendices. ${ }^{19}$

The decline in incidence of appendicitis is also confirmed by a fall in general practitioner consultation rates between 1955-6 and $1970-1 .^{20} \mathrm{~A}$ postwar decline in incidence has been recorded in other European countries ${ }^{21}$ and in the USA. ${ }^{22} 23$

\section{SOCIAL CLASS}

When appendicitis first appeared in Britain it was commoner among the rich. ${ }^{9}$ For example, in 1921-3 mortality in men aged 2065 was $15 \cdot 1$ per 100000 in social class I compared with 6.2 in social class V. ${ }^{15}$ Recent data from the 1970 birth cohort of British children show that this social class gradient has persisted. Appendicectomy prevalences at 10 years of age were $1.9 \%$ in social classes I and II, $1 \cdot 5 \%$ in social class III, and $1 \cdot 1 \%$ in social classes IV and $\mathrm{V}$ (Golding $\mathrm{J}$, personal communication).

\section{Dietary changes}

Figure 3, showing trends for cereal and vegetable fibre, meat and sugar, is based on national estimates of food supplies and consumption, published at intervals since 1880 and summarised ip two recent publications. ${ }^{24}$ While cereal fibre intake fell fron $12 \cdot 2 \mathrm{~g}$ per person per day in 1880 to $8 \cdot 1$ in 1970 , vegetable fibr $\$$ increased from $9.6 \mathrm{~g}$ to $11.5 \mathrm{~g}$. Daily total fibre consumption pefperson did not differ greatly in 1880 and 1970 . The use of highe $\widehat{\widehat{D}}$ extraction national wheat flours from 1942 until 1953 temporarily increased cereal fibre intake to around $22 \mathrm{~g}$. Vegetable fibre intake्ठ also increased during the second world war so that total fibre was around $37 \mathrm{~g}$.

From around 1880 onwards there was a steep increase in: consumption of imported meat. ${ }^{26}$ Total meat consumption-tha應 is, imported and home produced-rose from $41 \mathrm{~kg}(91 \mathrm{lb})$ carcase meat per head per year in 1880 to $60 \mathrm{~kg}(131 \mathrm{lb})$ in $1909-13 . \frac{5}{5}$

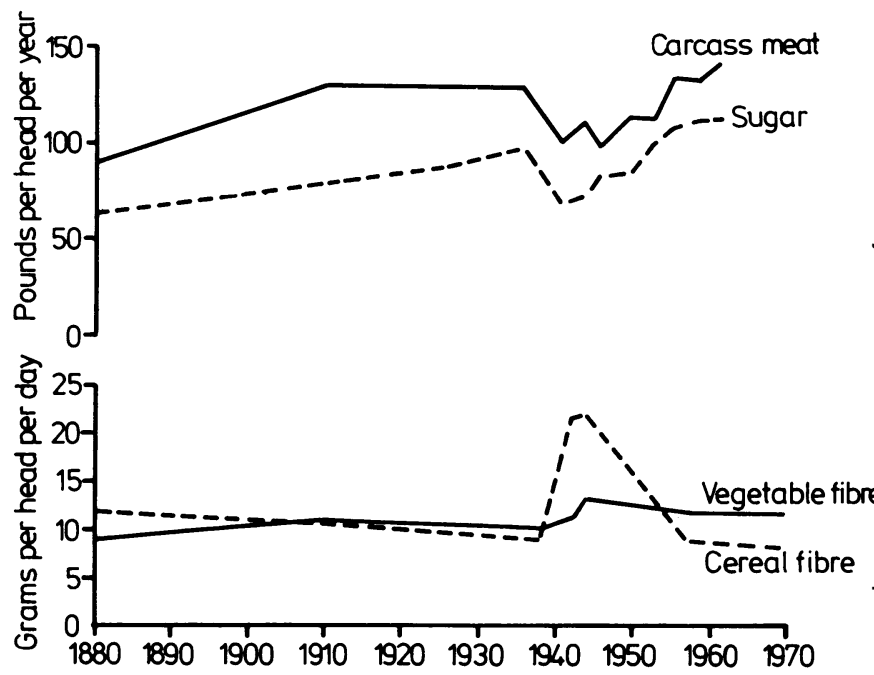

FIG 3-Trends in United Kingdom food supplies from 1880. (Based on Southgate $a l^{24}$ and Greaves and Hollingsworth. ${ }^{25}$ )

Consumption fell transiently during the first world war and them was steady until the second war, when it fell to below $45 \mathrm{~kg}$ (10® lb). By 1956 it had returned to prewar levels.

The rise in sugar consumption from around 1845 onwards was one of the oustanding changes in the British diet. By 1889 consumption had reached $29 \mathrm{~kg}(64 \mathrm{lb})$ per person per yearo Thereafter it rose progressively except during both wars, when is declined. In the second war it fell back to levels approaching those in 1880 but returned to prewar levels by 1953 .

\section{Discussion}

Of all the diseases implicated by the dietary fibre hypothesis $\frac{\text { O }}{2}$ appendicitis is arguably the most susceptible to analyses based on time trends. It occurs mainly in children and young adults and its incidence is therefore likely to respond more swiftly to environo mental changes than diseases of later life-where there may be lengthy latent periods of unknown duration. Most episodes of appendicitis are emergencies ending in operation; therefore it ${ }^{5}$ frequency has been well documented. Over the years so much has? been written about the disease that knowledge of case fatalityo

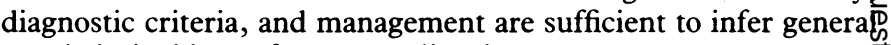
trends in incidence from mortality data.

The upsurge in the disease from around 1895 may have beent exaggerated by more widespread recognition. Its decline, a reflected in mortality, may have been accelerated by changin diagnostic practices in patients with abdominal pain, changin $\mathbb{8}$ criteria for appendicectomy, and falling case fatality. Nevertheless the overall pattern is clear-a steep rise which began abruptlg around 1895 and a steep fall from the 1930s onwards.

There are limitations to the dietary data. The estimates of national food supply in the early years are uncertain. Calculations. of average consumption per person have less meaning when the 
distribution of food between social groups is appreciably uneven, as it was in the past. Likewise diets of children and young adults may not be well described by average figures. Despite these limitations the data are probably adequate as indicators of general trends.

Clearly the decline in appendicitis does not correlate with changes in fibre, meat, or sugar. Moreover, there is little to support the conclusion that the decline was initiated by the major changes in the British diet during the second world war $^{2728}$; nor does fig 2 point clearly to a wartime acceleration of a decline which had already begun.

If the large rise in incidence, from rarity to around 50 cases per 10000 population per year, was the effect of changing levels of consumption of a particular food, the new levels must be associated with a high risk, both absolute risk and risk relative to that in the population before the change. Given the variations among individual diets which still exist within the population, a food associated at certain levels of consumption with a high risk of disease should be readily identified in comparisons of the diets of cases of appendicitis and controls. This has not proved to be so; the results of case-control studies have been inconclusive. ${ }^{29.31}$

If changes in consumption of a food caused the upsurge of appendicitis the 1880 consumption levels must be regarded as thresholds above which (for fibre) or below which (for meat or sugar) the disease is rarely induced. Such an interpretation, however, is not consistent with the trends during and after the second world war. At that time both cereal and vegetable fibre consumption were appreciably above the 1880 levels, and meat and sugar consumption fell to levels close to those in 1880 . Given a latent period no longer than a few years, at least in children, these dietary changes would be predicted to cause a sharp drop in appendicitis in the 1940s, followed by a rise in incidence in the 1950s when food rationing ceased. There is no evidence that this occurred.

Interaction between several dietary influences offers a readier explanation of the rise because dietary influences such as meat and fibre vary together, historically and cross culturally, to an extent which may make it impossible to separate their effects. Several influences interacting multiplicatively, as is usual, would be less easily identified in case-control studies than a single dominant influence. Nevertheless, the lack of response of appendicitis trends to dietary changes during and after the second world war remains inexplicable. Consideration of the first world war adds little. The temporary decline in appendicitis in older women, but not children, at a time of shortages of many foods including meat and sugar may have been a consequence of a fall in total food intake. There are reports of considerable falls in appendicitis incidence in Russia and Germany during periods of starvation..$^{102}$

It may be concluded that dietary changes during the past century do not offer a sufficient explanation for either the rise or the decline of appendicitis in Britain. In particular, a close dependence on dietary fibre intake, postulated 60 years ago, and the origin of the hypothesis linking fibre to a range of "Western diseases," does not withstand critical examination of trends.

The time trends are more readily explained by the hypothesis that appendicitis is primarily an infectious disease. Many infections, spread by way of the alimentary or respiratory tracts, are known to be associated with the high risk of disease implied by the large rise in appendicitis at the turn of the century.

In 1932 Aschoff showed that the ultimate event in appendicitis was invasion of the distal appendicular wall by organisms habitually among the enteric flora. ${ }^{10}$ This remains the general view. ${ }^{32}$ Debate centres on the preceding pathological changes. In 1946 Bohrod argued that the initiating event in appendicitis was lymphoid hyperplasia in the appendicular wall and consequent obstruction of the proximal lumen. ${ }^{33} \mathrm{He}$ pointed out that this would explain the remarkably constant age distribution of the disease in different times and places, since the bulk of lymphoid tissue in the appendicular wall in relation to luminal size is maximal in the second decade of life. The theory also explains the absence of faecoliths, an alternative possible cause of luminal obstruction, in most removed appendices. ${ }^{5}$
The appendicitis epidemic in Britain started at the time when infections had begun to decline steeply, in consequence of improved living standards and sanitation. ${ }^{34}$ It may be postulated that decreased incidence of infection among children, especially in wealthier families, changed their pattern of immunity so that they responded to certain enteric or respiratory infections with lymphoid hyperplasia- which included the lymphoid tissue in the wall of the appendix. This changed pathogenic response to infections whose frequency in early childhood was declining would be analogous to the age-dependent consequences of infection with the poliomyelitis and Epstein-Barr viruses. Explanation of the fall in appendicitis may depend on continued changes in the population's immunity.

The hypothesis is able to explain the international distribution of appendicitis. Countries where it is common are characterised by lower incidences of infectious disease. The rising incidence of appendicitis among the more affluent, urbanised communities within non-industrialised countries may be explained by the improvement in the hygienic conditions of these communities.

The hypothesis that appendicitis is primarily a response to systemic infection with viruses or bacteria does not exclude a role for diet-perhaps mediated through changes in the appendicular flora and hence the likelihood of mucosal invasion following luminal obstruction. A recent analysis in 65 local authority areas within Britain showed no correlation between appendicitis incidence and cereal fibre intake, but a strong negative correlation with green vegetable consumption and a positive correlation with potato consumption (unpublished data).

I am grateful to my colleagues Dr D N M Coggon, Dr A J Hall, and Dr M Nelson for their comments on this paper; to Mrs Shirley Simmonds, who helped with the library search; and to Mrs Bridget Wilde, who typed the manuscript.

\section{References}

1 Rendle Short A. The causation of appendicitis. Br I Surg 1920;8:171-88.

2 Williams OT. The distribution of appendicitis, with some observations on its relation to diet. $B r$ Med J 1910;ii:2016-21.

3 Murray RW. The geographical distribution of appendicitis. Lancet 1914;ii:227-30.

4 Burkitt DP. The aetiology of appendicitis. Br f Surg 1971;58:695-9.

5 Trowell HC, Burkitt DP. Western diseases: their emergence and prevention. London: Edward Arnold, 1981 .

6 Burkitt DP. In: Birch GG, Parker KJ, eds. Dietary fibre. London and New York: Applied Science, 1983.

7 The Registrar General's statistical review of England and Wales: Part I Tables, Medical. London: HMSO, 1901 and following years.

8 Collins DC. Historic phases of appendicitis. Ann Surg 1931;94:179-96.

9 Spencer AM. Aetiology of acute appendicitis. Br Med f 1938;i:227-30.

9 Spencer AM. Aetiology of acute appendicitis. Br Med $\mathcal{J}$ 1938;i:227-30.
10 Aschoff L. (Translated by Pether GC.) Appendicitis, its aetiology and pathology. London: Constable, 1932

11 Special correspondence. $\mathrm{Br}$ Med $\mathcal{J}$ 1903;i:1373.

12 Gazeta dos Hospitaes do Porto. (Quoted in) Br Med J 1908;ii:191.

13 Anonymous. Nottingham Medico-Chirurgical Society. [Editorial.] Lancet 1910;ii: 1835

14 Fitz RH. Perforating inflammation of the vermiform appendix. Am J Med Sci 1886;184:321-45

15 Young M, Russell WT. Appendicitis, a statistical study. Medical Research Council Special Repor Series No 233. London: HMSO, 1939.

16 Boyce FF. Acute appendicitis and its complications. New York: Oxford University Press, 1949.

17 Report on the hospital in-patient enquiry. London: HMSO, 1957 and following years.

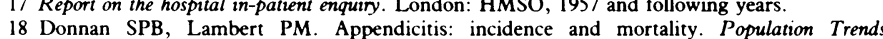
1976;5:26-8.

19 Raguveer-Saran MK, Keddie NC. The falling incidence of appendicitis. Br $\mathcal{F}$ Surg 1980;67:681

20 Mortality statistics from general practice, studies on medical and population subjects. No 14 and 26 London: HMSO, 1958 and 1975

21 Arnbjornsson E, Asp NG, Westin SI. Decreasing incidence of acute appendicitis with special reference to the consumption of dietary fiber. Acta Chir Scand 1982; 148:461-4.

22 Castleton KB, Puestow CB, Sauer D. Is appendicitis decreasing in frequency? Arch Surg 1959;78:794-801.

23 Palumbo LT. Appendicitis-is it on the wane? Am $\mathcal{X}$ Surg 1959;98:702-3.

24 Southgate DAT, Bingham S, Robertson J. Dietary fibre in the British diet. Nature 1978;274: $51-2$.

25 Greaves JP, Hollingsworth DF. Trends in food consumption in the United Kingdom. World Rev Nutr Diet 1966;6:34-89.

26 Annual abstracts of statistics. London: HMSO, 1880 and following years.

28 Donnan SPB. Aetiology of appendicitis. Br Med J 1979;i:1215.

29 Cove-Smith JR, Langman MJS. Appendicitis and dietary fibre. Gut 1975;16:409.

30 Nelson M, Barker DJP, Winter PD. Dietary fibre and acute appendicitis: a case-control study Human Nutr: Appl Nutr 1984;38A:126-31.

31 Arnbjornsson E. Acute appendicitis and dietary fiber. Arch Surg 1983;118:868-70.

32 Pieper R, Kager L, Weintraub A, Lindberg AA, Nord CE. The role of bacteroides fragilis in the pathogenesis of acute appendicitis. Acta Chir Scand 1982;148:39-44

33 Bohrod MG. The pathogenesis of acute appendicitis. Am f Clin Path 1946;16:752-60.

34 McKeown T, Lowe CR. An introduction to social medicine. Oxford: Blackwell, 1977.

(Accepted 3 Januany 1985) 